Cómo citar este artículo en Chicago: Covarrubias Correa, Andrés. "Las pasiones dolorosas y su tratamiento en la Retórica de Aristóteles".

Escritos 29, no. 63 (2021): 213-224._doi: http://doi.org/10.18566/escr.v29n63.a01

Fecha de recepción: 03.03 .2021

Fecha de aceptación: 27.04.2021

\title{
Las pasiones dolorosas y su tratamiento en la Retórica de Aristóteles
}

\author{
Painful passions and their treatment in Aristotle's Rhetoric
}

\author{
Andrés Covarrubias Correa ${ }^{1}$
}

\section{RESUMEN}

Este artículo atiende a la importancia de las pasiones y su componente de dolor y placer en la reflexión ética de Aristóteles. Después, y asumiendo estos antecedentes, analiza la ira y la calma desde el punto de vista de la Retórica, para finalmente ocuparse de una manera más amplia, sobre todo, en busca de aspectos comunes, de las otras pasiones dolorosas descritas en esta obra. Plantea que la Retórica entrega importantes herramientas no solo para provocar o mitigar una pasión, sino para poder reconducirla de manera que sea útil para el buen orador ante el mejoramiento de los ciudadanos. Esto significa concebir las pasiones, que tienen en su origen un carácter eminentemente individual, también como compartidas por una comunidad. A partir del análisis de estos textos y de las consecuencias que se derivan del estudio de las pasiones dolorosas, es posible extraer valiosos elementos que permiten enriquecer nuestra comprensión de aquellos aspectos que influyen en la vida comunitaria y política, sobre todo, en consideración al lugar preponderante que tales pasiones van adquiriendo en condiciones históricas difíciles, como en la práctica ocurre con la actual situación de pandemia que nos ha tocado enfrentar globalmente.

Palabras clave: Aristóteles; Ética; Retórica; Placer; Dolor; Pasiones dolorosas; Ira; Calma; Sanación; Comunidad política.

\begin{abstract}
This article addresses the importance of passions and their component of pain and pleasure in Aristotle's ethical reflection. Then, and assuming these antecedents, it analyzes anger and calm from the point of view of Rhetoric, to finally deal with the other painful passions described in this work in a broader way, in search of common aspects. $\mathrm{He}$ argues that Rhetoric provides important tools not only to provoke or mitigate a passion, but also to be able to redirect it in a way that is useful for a good speaker in the face of citizen improvement. This implies conceiving the passions, which have an eminently individual character at their origin, also as shared by a community. From the analysis of these texts and the consequences that derive from the study of painful passions, it is possible to
\end{abstract}

1 Doctor en Filosofía por la Universidad de Granada, España. Profesor del Instituto de Filosofía, Pontificia Universidad Católica de Chile. Correo electrónico: acovarrc@uc.cl. 
extract valuable elements that allow us to enrich our understanding of those aspects that influence community and political life, especially in consideration of the forefront that such passions are acquiring in difficult historical conditions, as it occurs in practice with the current pandemic situation that we have had to face globally.

Keywords: Aristotle; Ethics; Rhetoric; Pleasure; Pain; Painful Passions; Anger; Calm; Healing; Political community.

\section{Introducción}

$\mathrm{L}$

a Retórica, de Aristóteles, muestra una gran complejidad en lo que respecta a sus alcances éticos, pues, mientras hay quienes realizan una lectura intrínsecamente ética de esta obra, hay otros que defienden su independencia en este campo. También se ha intentado vincular la posición aristotélica con una moral popular. En efecto, diversos textos del Estagirita permiten sostener estas distintas interpretaciones. Si bien hay quienes ponen énfasis en el hecho de que no se debe persuadir sobre lo malo y en que la justicia es superior a su contrario, otras líneas interpretativas marcan el acento en su independencia en tanto es una téchne del horizonte de lo ético, sobre todo en atención a su capacidad de persuadir sobre las cosas contrarias. Debido a lo anterior, el problema capital abordado involucra la posición que se tome respecto de la continuidad o no del proyecto platónico elaborado en el Fedro por parte de Aristóteles. ${ }^{2}$

A partir de este diagnóstico, considero que es posible proponer una vía diferente de interpretación, con énfasis en el tratamiento de las pasiones dolorosas en la Retórica y cómo estas nos ofrecen un nuevo punto de vista para afrontar este arduo problema. Así pues, nuestra metodología está circunscrita al análisis de los textos en los que Aristóteles aborda tales pasiones y cómo desde ellas se despliega la posibilidad de concebir la actividad del orador como una terapia orientada al bien de la comunidad política, a diferencia de lo que han realizado hasta entonces, según el Estagirita, los demagogos y logógrafos. ${ }^{3}$ Esto permite una aproximación de la posición de Platón y la de su discípulo, en el sentido de orientar la actividad oratoria hacia un mejoramiento de la vida comunitaria.

2 Es amplia la bibliografía respecto del problema planteado. Puede revisarse, por ejemplo, Robert Price, "On the Place of Validity", Philosophy and Rhethoric 25 (1992): 341-350, quien argumenta a favor del intento platónico en el Fedro tendiente a legitimar los razonamientos que superan el horizonte de lo verosímil, aproximando tal obra a la Retórica aristotélica, en el sentido de que ambos filósofos buscan construir silogismos cuyas conclusiones obtengan un carácter de necesidad y, por tanto, logren una mayor validez. Esto avalaría una cierta continuidad del proyecto platónico en el camino intentado después por Aristóteles. En esta misma línea, se puede considerar también a Michel Meyer, The Modernity of Rhetoric (Norwell: Kluwer, 1989). Sin embargo, Douglas Hutchinson marca las diferencias entre la posición platónica y la aristotélica respecto de la retórica afirmando que Aristóteles, incluso, invierte muchas de las ideas platónicas acerca de la virtud, siguiendo, en parte, una línea semejante a la de Isócrates. "Doctrines of the Mean and the Debate Concerning Skills in Fourth-Century Medicine, Rhetoric and Ethics", Apeiron 21, no. 2 (1988): 17-52. En un sentido similar, y en relación con las pasiones, argumenta Eckart Schütrumpf, "Non-Logical Means of Persuasion in Aristotle's Rhetoric and Cicero's De oratore", en Peripatetic Rhetoric After Aristotle, ed. por William Fortenbaugh y David Mirhady (New Brunswick: Transaction Publishers, 1994), 106-110. Por su parte, William Fortenbaugh propone la superación por parte del Estagirita de la concepción que Platón tenía de las emociones. Aristotle on Emotion: A Contribution to Philosophical Psychology, Rhetoric, Poetics, Politics, and Ethics (Londres: Duckworth, 1975).

3 La dimensión terapéutica en lo que hace relación con el placer y el dolor, y cómo esa sanación puede provenir de los contrarios, es explicitada por Aristóteles en Ética eudemia II, 1, 1220a. Asimismo, enriquece esta visión del alma la estrecha relación que el Estagirita percibe entre las pasiones del alma y su expresión corporal (Acerca del alma 403a 18-24). 
Este camino interpretativo nos lleva, desde una consideración de las pasiones a partir de los escritos ético-políticos de Aristóteles, hasta la Retórica. En este texto, haremos hincapié, a modo de ejemplo, en el análisis de la ira y la calma, puesto que son pasiones fuertemente arraigadas en el ámbito judicial y político, y por tanto muy relevantes en el contexto de la vida pública, para finalmente aplicar estas consideraciones a las demás pasiones dolorosas descritas en el libro II de esta obra. ${ }^{4}$

\section{Dimensión ética de las pasiones y la Retórica}

Para Aristóteles, no solo es relevante el conocimiento de las pasiones dolorosas en sí mismas, sino que también solo conociéndolas es como se hace posible su adecuada superación cuando podemos conducirlas a su pasión contraria. En este sentido, se puede afirmar que acompaña esencialmente al tratamiento de las pasiones dolorosas la posibilidad de su sanación mediante el lenguaje persuasivo, al poderlas reconducir de manera adecuada hacia su contrario, por ejemplo, de la ira a la calma. ${ }^{5}$

Aristóteles en Ética a Nicómaco II, 5, al considerar qué es la virtud, indica que en el alma hay pasiones, facultades y hábitos, y que se debe determinar a cuál de ellos pertenece la areté. Plantea que las pasiones son afectos acompañados de placer o dolor, las facultades son aquellas por las que se dice que nos afectan las pasiones y, en fin, se entiende por hábitos aquello en razón de lo cual nos comportamos bien o mal en relación con las pasiones. Así pues, no se nos llama buenos o malos, o se nos elogia y censura, por tener determinadas pasiones, sino por la actitud que adoptamos frente a ellas, por sentirlas en una medida adecuada a las circunstancias y en atención a su duración oportuna. En definitiva, son estas últimas las que nos mueven, a diferencia de las virtudes y de los vicios que solo nos dan cierta disposición habitual. Además, en Ética a Nicómaco III, 1, se vuelve a explicitar que la virtud tiene por objeto pasiones y acciones (1109b 30).

Este análisis centrado en la virtud nos ofrece un importante reflejo del horizonte en que nacen e influyen las pasiones, con su correspondiente efecto de placer y dolor en quien las siente y la posibilidad de que ellas puedan ser influenciadas por argumentos. En efecto, Aristóteles plantea, en el contexto de su caracterización de las pasiones, que los argumentos verdaderos no solo son útiles para el conocimiento, sino también para vivir, y la razón de esto es que al armonizar con los hechos se les da crédito, y así mueven a quienes los comprenden a conducir su existencia de acuerdo con tales razonamientos (Ética $a$ Nicómaco X, 1, 1172b 4-7).

4 Sobre el lugar central de las pasiones en la retórica deliberativa o política, en el contexto de la importancia de la legislación para la salvación de la ciudad, véase Óscar Godoy, La democracia en Aristóteles: Los orígenes del régimen republicano (Santiago de Chile: Universidad Católica de Chile, 2012), 336-342.

5 Dorothea Frede expone las razones por las que Aristóteles acepta en la Retórica, a diferencia de la Ética a Nicómaco, el tratamiento médico de las pasiones desarrollado por Platón: “The Platonic-Aristotelian medical conception of the emotions as complex mixtures of pleasures and pains that involve beliefs and expectation explains, for instance, why we don't apply an ice bag when people are red-hot with anger, but appease them instead through reasoning with them. We will tell them, for instance, that the perpetrator did not mean to slight them, or that he is beneath their notice, or that it is in vain to seek redress. In short, we try to change the people's beliefs, rather than their temperature, because a change of belief will also change their feelings". "Mixed Feelings in Aristotle's Rhetoric", en Essays on Aristotle's Rhetoric, ed. por Amelie Oksenberg Rorty (Berkeley: University of California Press, 1996), 271-272. 
En lo que respecta a la Retórica, vista en su trasfondo ético, hay opiniones que favorecen muy fuertemente una conexión estrecha entre las pasiones y su componente cognoscitivo: "Si la opinión popular sostiene que la cólera es un apetito corporal bruto y ajeno a todo razonamiento, un fuego en el corazón, mientras que la verdad sobre la cólera es que es una disposición cognitiva compleja basada en creencias de diversas clases, entonces es esta segunda opinión, no la primera, la que el orador ha de conocer, puesto que su objetivo no es hablar de la cólera, sino producirla". 6 También se afirma que hay en la Retórica una fundamentación y conexión desplegada desde una perspectiva filosófica, en que "son reinsertadas en la retórica nociones filosóficas cruciales", que incluyen el estudio de las pasiones y caracteres y, de este modo, "la Retórica de Aristóteles crea una vinculación estrecha entre retórica y filosofía." Hay otras posiciones, en cambio, que circunscriben tanto el carácter como las pasiones en una dimensión marcadamente irracional de la retórica aristotélica sin atender suficientemente a los procesos cognitivos posiblemente involucrados. ${ }^{8}$ Finalmente, también hay comentaristas que optan por una vía media respecto de la posición de Nussbaum, matizan el fuerte componente cognoscitivo que esta autora adjudica a las pasiones y proponen más bien una interpretación cognitivista moderada. ${ }^{9}$

Desde mi punto de vista, una respuesta consistente que puede complementar la discusión de los comentaristas del Estagirita viene dada por la relación entre la razón y los elementos irracionales que se dejan persuadir por la razón. Este es el caso de la tragedia, por ejemplo, en que el pensamiento (diánoia), a cargo de la retórica, es el que tiene el mayor efecto en el sentido de excitar las pasiones (Poética 1450b 4-8 y 1456a 33-b 2), lo que aporta una buena razón para vincular las pasiones con los argumentos, desde el ámbito del lenguaje y todo esto mediante un recurso persuasivo.

Pero, en lo fundamental, considero que el texto más significativo está en el libro I, capítulo 13, de la Ética a Nicómaco (1102b 29-1103a 10), ya que en este pasaje se expresa que lo irracional se puede dividir en lo vegetativo, que no participa de la razón, y lo apetitivo, y en general lo desiderativo, que participa de ella en cuanto le es dócil y obediente o persuadible (peitharchikón), como puede ocurrir con el consejo recibido del padre o de los amigos: "Que lo irracional se deja en cierto modo persuadir (peíthetaí) por la razón lo indica también la advertencia y toda reprensión o exhortación. Y si hay que decir que esto también tiene razón, lo que tiene razón será doble, de un lado primariamente y en sí mismo, de otra parte como hacer caso al padre" (1102b 34-1103a 3).

6 Martha Nussbaum, La terapia del deseo: Teoría y práctica en la ética helenística. Trad. por Miguel Candel (Barcelona: Paidós, 2003), 116.

7 Laurent Penrot, La retórica en Grecia y Roma (México: Universidad Nacional Autónoma de México, 2013), 281.

8 Antonio López Eire, Sobre el carácter retórico del lenguaje y de cómo los antiguos griegos lo descubrieron (México: Universidad Nacional Autónoma de México, 2005), 119-126; Juan Fernando Sellés-Dauder, Los filósofos y los sentimientos (Pamplona: Universidad de Navarra, 2010), 14-15.

9 Carmen Trueba realiza un detallado y sugerente análisis de las diversas posiciones de algunos comentaristas principales en torno a las emociones, destacando que en Aristóteles se presenta un complejo haz de aspectos que afectan a las emociones, los que participan de distinta manera según la emoción de que se trate. Pero, en general, las emociones son afecciones psicofísicas que involucran: "1) alteraciones y procesos fisiológicos, 2) sensaciones de placer y/o dolor, 3) estados o procesos cognitivos tales como: a) sensaciones o percepciones (aisthesis), b) impresiones sensibles y/o impresiones racionales (phantasia), c) creencias (doxai) o juicios (hypolepsis) (ya sea una de estas tres operaciones cognitivas o diferentes combinaciones posibles entre ellas, según el tipo y el grado de complejidad de la emoción), 4) actitudes y disposiciones hacia el mundo y 5) deseos o impulsos (orexis)". "La teoría aristotélica de las emociones", Signos Filosóficos 11, no. 22 (2009): 167. 
Así pues, tal como desde la perspectiva de la Ética a Nicómaco hay elementos irracionales que, sin embargo, se dejan persuadir por la razón, de una manera semejante el orador debería actuar como un agente dotado de razón persuasiva al intentar influir en las pasiones del auditorio, en tanto estas últimas, las páthe, constituyen una de las tres pruebas técnicas (éntechnoi písteis) propuestas por Aristóteles en la Retórica. Pero, para que ocurra esto, el sujeto de las pasiones debe prestar un cierto oído para poder ser persuadido respecto de sus sentimientos, tal como el hijo debería actuar frente a los consejos de su padre, o como atendemos a nuestros amigos buenos cuando nos aconsejan bien, siguiendo el ejemplo que propone el Estagirita en el texto recién citado de Ética a Nicómaco. No me refiero a los deseos o apetitos corporales que se puedan despertar casi automáticamente en el cuerpo por necesidad, como puede ser el impulso de saciar el hambre o la sed, ${ }^{10}$ sino a las pasiones que se entretejen en el alma, y la engrandecen o empequeñecen, en un lapso más amplio de tiempo, como el amor o la envidia, en aquellas cosas que pueden ser de más de una manera e, incluso, contrarias. En esto, tal vez el buen orador debe hablar, aconsejar, disuadir, recriminar y alentar, como lo haría un buen padre a su hijo, o como lo hacen los amigos, observando, sobre todo, el bien de la pólis. Tal vez en apoyo de esa autoridad paterna o proveniente de la amistad es que el orador debe aparecer, prescindiendo de las demostraciones, como benevolente, sensato y virtuoso en lo que respecta a su carácter (éthos), en tanto este es el segundo tipo de prueba retórica (Retórica II, 1378a 8), junto con las pruebas lógicas, el entimema y el ejemplo, y las pasiones. ${ }^{11}$

Quizá frente a la diversidad de opiniones de los comentaristas y en relación con la opción interpretativa que asumo, sobre todo a partir del capítulo final del libro I de la Ética a Nicómaco, es un buen método analizar con más detalle ciertas pasiones acogidas en la Retórica con el fin de aportar mayor claridad al problema que se plantea.

\section{Ira y calma: el pesar y su mitigación en la Retórica}

En atención a que las pasiones no podrían constituirse en pruebas propias del arte retórico si no se las pudiera vincular a una causa racional, dado que las téchnai exigen el conocimiento de un principio creador, en razón de que la téchne es una de las virtudes dianoéticas, y que, en este sentido, al menos algunas de ellas, las tratadas en la Retórica, deben incluir un componente de razonabilidad, un primer aspecto que llama la atención en el tratamiento de las pasiones en el libro II es el hecho de que comienza con la ira, y deja las demás páthe para una consideración posterior. A mi juicio, no se trata de un orden arbitrario, sino que está íntimamente relacionado con el hecho de que las pasiones, entre las que se encuentra

10 Alejandro Vigo analiza las diferencias entre los rasgos específicos que distinguen a la agencia racional, por una parte, del mero movimiento animal, por otra, en atención, sobre todo, a las características y consecuencias del silogismo práctico. Aristóteles: Una introducción (Santiago de Chile: Instituto de Estudios de la Sociedad, 2006), 110-114. Como complemento a esto, véase Nussbaum, La terapia del deseo, 115.

11 Una posible objeción a este vínculo entre los razonamientos y las pasiones proviene de la misma Retórica, en que Aristóteles afirma que, cuando se trata de provocar una pasión, no se debe usar un entimema, porque, o se apagará la pasión, o será inútil el enthýmema, ya que dos movimientos opuestos y simultáneos se repelen entre sí, los neutralizan o los vuelven débiles (1418a 12-15). A mi juicio, esta dificultad es solo aparente, toda vez que se trata, en el caso de las páthe, de pensamientos y fantasías que acompañan y suscitan las emociones, y no del componente propiamente lógico de las pruebas retóricas desde un punto de vista estrictamente técnico, tendiente a superar la mera demagogia o la incapacidad de persuadir adecuadamente tal como es explicitado por el Estagirita en Política 1304b 20-24 y 1305a 7-15. 
la ira, preferentemente son abordadas en el contexto de la retórica judicial y su auditorio (Retórica 1377b 28-31), ${ }^{12}$ en que se busca, sobre todo, la reparación de un daño real o aparentemente causado, o, también, que podría haber sido realizado y no se logró llevar a cumplimiento, a un determinado sujeto o a quienes le son cercanos, lo que ciertamente produce ira en quien se siente afectado por tal perjuicio real o presunto. ${ }^{13}$

Aristóteles define la ira (orgé) como "un apetito (órexis) penoso de venganza por causa de un desprecio manifestado contra uno mismo o contra los que nos son próximos, sin que hubiera razón para tal desprecio" (Retórica 1378a 30-32). ${ }^{14}$ Se distingue del odio (mísos) porque este puede extenderse al género (por ejemplo, los ladrones o los delatores en su conjunto), y a diferencia de la ira, que puede tener cura con el tiempo (iaton chróno), el odio no se puede remediar o sanar (aníaton) (1382a 7-8). ${ }^{15}$ Puesto que el iracundo se encoleriza contra un individuo particular, con el que podría eventualmente llevar a cabo su revancha, el que odia, en cambio, no tiene pesar que pueda ser subsanado, sino solo aspira a que el otro no exista, infligirle un daño por causa del mal mismo, y por eso jamás se compadece. ${ }^{16}$ La ira, pues, es seguida por un cierto placer, que tiene su origen en la esperanza de obtener venganza, ya que es placentero pensar que está a nuestro alcance, mediante la fantasía, aquello que se desea, lo que el Estagirita compara con el placer que pueden producir a veces los sueños.

Tal como se hace muy patente en la definición de la ira, su principal motivación está en la sensación de haber sido objeto de desprecio. En este último, se hace evidente la opinión de que algo, o alguien, no tiene un real valor para determinada persona. Aristóteles establece que sus especies son el desdén, la vejación y el ultraje. Aunque las definiciones de estas tres especies y sus diferencias aportan un material invaluable para la consideración de la psicología aristotélica, lo que importa ahora subrayar es que en todas las dimensiones y matices del desprecio está el denominador común de la desvalorización de aquello que el otro aprecia y la falta de temor a una represalia que pudiera provenir del que se siente despreciado

12 Heinrich Lausberg, asumiendo la tradición retórica posterior, escribe que la peroratio constituye la última oportunidad para disponer al juez y al público de modo que sea favorecida la causa del orador y de influir desfavorablemente en la parte contraria, mientras que en las demás partes del discurso el uso de los afectos debe ser moderado. Manual de retórica literaria: Fundamentos de una ciencia de la literatura, vol. 1 (Madrid: Gredos, 1990), 364-366. Así pues, la ratio posita in affectibus se divide en la indignatio, que se dirige contra la parte contraria, y la conquestio, que busca lograr la simpatía hacia nuestra propia causa, de modo que son estos dos afectos los principales del genus iudiciale.

13 Es sugerente considerar, en lo que respecta a las pasiones, la posibilidad de ampliar el auditorio más allá del ámbito judicial, como cuando el orador usa un apóstrofe para expresar aquel páthos que no puede canalizarse por las vías normales de comunicación. David Pujante, Manual de retórica (Madrid: Castaglia, 2003), 262-264; Bernard Yack compara la importancia de las pasiones en la retórica jurídica y en la deliberativa o política, y muestra que en esta última el influjo de las páthe es aún más determinante, puesto que se orienta hacia el futuro. "Rhetoric and Public Reasoning: An Aristotelian Understanding of Political Deliberation”, Political Theory, 34, no. 4 (2006): 432-433.

14 Para un análisis detallado de esta definición y la importancia del apetito o deseo (órexis) en su formulación, véase John Cooper, "An Aristotelian Theory of the Emotions", en Essays on Aristotle's Rhetoric, ed. por Amelie Oksenberg Rorty (Berkeley : University of California Press, 1996), 249-250.

15 Alberto Bernabé traduce, en efecto, que la ira puede curarse con el tiempo, en tanto que el odio es incurable. Aristóteles, Retórica (Madrid: Alianza, 1998), 155.

16 En Política 1312b 25-34, Aristóteles describe la ira como una parte del odio y como causa de las mismas acciones y, a veces, es más activa que el odio porque en ella no es fácil razonar, puesto que va acompañada de dolor y, en cambio, el odio está libre de dolor. El Estagirita agrega en la Retórica el importante efecto que tiene aquello que puede ser sanado y aquello que no. 
o, simplemente, el desinterés por la posibilidad de cultivar o preservar su amistad. En definitiva, por el simple placer de hacer daño o sentirse superior avergonzando y deshonrando a otro, en el ultraje, o solo por entorpecer los anhelos de otro sin sacar provecho uno mismo, como es el caso de la vejación, mostramos nuestra actitud de profundo desprecio y carencia de temor frente a las consecuencias que se pudieran producir.

Encolerizarse, pues, implica un cierto pesar, y de este modo los que desean algo vehementemente y no logran satisfacer su pasión son iracundos, todavía más con quienes desprecian su condición, y aumenta esta pasión si esto ocurre inesperadamente y más con los amigos y próximos que con quienes no lo son. Esta pasión también surge contra quienes se burlan u ofenden gratuitamente. También se presenta la cólera contra los que desprecian o hablan mal de aquello que es de máximo interés para quien se siente despreciado, como aquellos que desdeñan la filosofía frente a quien la tiene en alta estima (Retórica 1379a 36-37), y esto ocurre, sobre todo, cuando el ofendido tiene la sospecha de no sobresalir suficientemente en aquello de que es objeto de desprecio o burla.

Se podrían considerar con más detalle las observaciones que aporta Aristóteles en relación con la ira, en el contexto de su descripción sobre contra quiénes se siente esta pasión, en qué disposiciones y por qué causas, pero eso nos alejaría de nuestro tema principal. Respecto del orador, lo importante es que mediante el discurso sea capaz de inclinar a los auditores de manera que sientan ira, y para esto es necesario presentar a los adversarios "a la vez como culpables de aquellas cosas por las que se siente ira y como sujetos de la índole propia para excitarla” (Retórica 1380a 2-5).

Tenemos, pues, que la ira supone una valorización de sí mismo y de aquellas cosas que tenemos en más alta estimación cuando están sujetas a un cierto desprecio, en el supuesto de que, sin embargo, no estamos totalmente seguros de que poseamos cabalmente aquello que parecemos estimar. En caso contrario, no se siente ira por tal maltrato, como cuando estamos seguros de nosotros mismos o de aquello que estimamos, y en este caso no tendrá un gran efecto el intento del orador por conducirnos a la ira. Lo interesante es que la retórica muestra tanto el camino que permite excitar ciertas pasiones dolorosas como, mirado inversamente, una terapia de tales sentimientos a partir de la descripción que Aristóteles realiza de estas pasiones. ${ }^{17}$ Esto adquiere especial relevancia por el hecho de que las pasiones son aquellos sentimientos que modifican al hombre hasta llegar a afectar sus juicios y que van acompañados de dolor o placer (Retórica II, 1, 1378a 20).

17 William Fortenbaugh defiende que las definiciones de las pasiones en la Retórica no son tanto un compendio de opiniones comunes como una respuesta a posiciones filosóficas nacidas en la Academia a partir de la consideración del placer y el dolor. "Aristotle's Rhetoric on Emotions", en Articles on Aristotle: Psychology \& Aesthetics, ed. por Jonathan Barnes, Malcolm Schofield y Richard Sorabji (Londres: Duckworth, 1979), 147. En este contexto, el comentarista afirma: "Aristotle's analysis of emotion and in particular of the essential involvement of cognition in emotional response is an important contribution to philosophical psychology. It is also important for rhetorical and ethical theory because it makes clear that emotions are not blind impulses. When a man responds emotionally, he is not the victim of some automatic reflex. On the contrary, he is acting according to his judgement". 
En efecto, lo contrario a encolerizarse es estar calmado, y así es como el Estagirita trata a continuación la calma (praótes). ${ }^{18}$ Conviene, en este sentido, preguntar en qué disposición están los calmos, ante quiénes permanecen tranquilos y las razones de este estado de quietud. Aristóteles define la calma como "un apaciguamiento y pacificación de la ira" (Retórica 1380a 8-9). La principal razón que permite conducir desde la ira a la calma es presentar como involuntario el desprecio que se ha recibido. También disminuye la ira respecto de quienes se presentan humildes.

Las cosas que producen calma Aristóteles las deduce de sus contrarios. Se está calmado frente a los que nos producen miedo o vergüenza. En general, uno no se encoleriza contra quienes se juzga que actuaron sin desprecio, como tampoco con los que lo hicieron con ira. El desprecio no implica pesar, la ira sí. Tampoco se siente cólera frente a quienes están avergonzados o piden perdón. También el transcurso del tiempo aplaca la ira o que no se vayan a percatar de nuestra ira aquellos que son objeto de ella. Y el Estagirita sintetiza:

Así pues, queda claro que los que quieren calmar a un auditorio deben obtener, a partir de estos lugares comunes, argumentos para disponerlos en el sentido de que aquellos contra quienes se siente ira, son tales que o bien inspiran temor o respeto, o bien les han hecho favores, o bien obraban sin querer, o bien ya están arrepentidos de lo que han hecho. (Retórica 1380b 31-34)

La conclusión que establece Aristóteles es clara en el sentido de poder reconducir aquellos sentimientos que podrían ser sanables, a diferencia del odio. Como ocurre con la amistad y la enemistad, hacer que las personas sean amigas si no lo son, o ponerlos en evidencia si lo andan afirmando falsamente, y, en fin, si por causa de la ira o la enemistad se vuelven nuestros adversarios, poder conducirlos en uno u otro sentido, según lo que cada cual desee (Retórica 1382a 16-19). Desde este punto de vista, el orador, al igual que el médico, que tanto puede sanar como matar con pericia, tiene las herramientas necesarias para poder realizar las cosas contrarias mediante el discurso persuasivo. Pero, al buscar una polis saludable, el orador debería actuar como lo hace un buen médico, es decir, no intentar eliminar las pasiones, puesto que siempre estarán profusa y fuertemente presentes, tal como lo entendieron los sofistas, ${ }^{19}$ sino tratarlas de manera que sean sentidas de un modo adecuado y en el tiempo oportuno para bien de la comunidad y los ciudadanos.

18 Médéric Dufour destaca que, mientras la cólera es concebida como un exceso, la calma lo es como una disposición media (mesotés), en relación con la teoría ética del justo medio y, por esto, un retorno al estado normal ("retour à létat normal ou moyen”). Aristote Rhétorique, livre II (París: Les Belles Lettres, 1991), 22. Considero sugerente la referencia a la normalidad por parte de este comentarista, toda vez que se puede vincular con una vuelta a una estado saludable para el alma en el sentido que hemos venido argumentando en este artículo.

19 Bernard Jacob argumenta consistentemente sobre la importancia de reconsiderar, desde la Retórica, la posición de Aristóteles en torno a la crítica, pero también la valoración de los aportes de algunos sofistas. "What If Aristotle Took Sophists Seriously? New Readings in Aristotle’s Rhetoric”, Rhetoric Review 14, no. 2 (1996): 237-252. 


\section{Otras pasiones dolorosas: el pesar y la turbación como denominador común}

A partir del ejemplo de la ira y su contrario, la calma, hemos hecho hincapié en la relevancia que tiene el pesar en la definición de las pasiones dolorosas, tomando como ejemplo la cólera provocada por la fantasía de que hemos sido objeto de algún desprecio o vejación, o bien que los han sufrido o podrían hacerlo algunos de nuestros próximos. De aquí la relevancia que tiene aprender a complacerse y dolerse como es debido en cuanto objetivo de la buena educación, asumiendo que los seres humanos, como los otros animales, tienden a lo agradable y a huir de lo doloroso, y esto los educadores lo utilizan desde la infancia con vistas a una adecuada formación (Ética a Nicómaco X, 9, 1179b 20-31 y X, 1, 1172a 19-21).

En un caso semejante a las pasiones mencionadas, está el temor en tanto es un pesar nacido de la imagen de que es inminente un mal destructivo (Retórica 1382a 21-22); ${ }^{20}$ la vergüenza, por ser un cierto pesar relativo a aquellos vicios actuales, pasados o venideros, cuya presencia implica una pérdida de prestigio (1383b 12-15); la compasión, como un pesar por la irrupción, que se presenta como próxima, de un mal destructivo y penoso en quien no lo merece, y que también podríamos esperar que lo sufriera uno mismo o alguno de nuestros cercanos (1385b 13-16); la indignación como un pesar por los éxitos ajenos inmerecidos (1386b 10-11); la envidia en tanto es un dolor por el éxito en las cosas buenas de nuestros iguales, sin que se obtenga algún provecho propio a partir de ese sentimiento (1387b 22-26); y, finalmente, la emulación (zelos), que se caracteriza por la manifestación de un pesar por algunos bienes honorables que uno debería alcanzar como lo han hecho nuestros iguales y que, a la vez, estimamos como posibles de conseguir para nosotros (1388a 32-36).

Al considerar la teoría de la persuasión aristotélica, y poniendo atención en las pasiones dolorosas, podemos constatar cómo estas se dejan influenciar por argumentos, y esto da cabida a una posibilidad de sanación, tal como el Estagirita lo indica explícitamente respecto de la ira, en su diferenciación con el odio, que se describe como incurable. El buen orador, pues, tiene el poder de reconducir las pasiones de tal manera que ellas deriven en sus contrarios, $\mathrm{y}$ así el alma pueda vivenciar un estado de placer, por ejemplo, en el caso de la ira, ser conducida hacia su contrario, la calma. Lo mismo puede ocurrir, correspondientemente, con todas las demás pasiones que provocan dolor. Por supuesto que la retórica, al poder persuadir sobre los contrarios, también puede suscitar desde las pasiones que no implican dolor una dolorosa. Más aún si sabemos que, para Aristóteles, la ira no es algo malo en sí mismo, sino que lo es cuando se siente de modo inadecuado o con quien no corresponde, es decir, cuando aparece como desproporcionada respecto de su objeto de aversión, o en relación con el tiempo en la que ha de ser vivenciada, y algo semejante ocurre con las otras pasiones mencionadas. El hecho de sentir tal dolor, de un modo adecuado y por el tiempo oportuno, también puede ir en beneficio de los ciudadanos, en el sentido de dar a las pasiones una función próxima a la kátharsis, tal como es

20 Para un análisis detallado de esta pasión, véase Andrés Covarrubias Correa, "Confianza y temor en Aristóteles", Philosophia: Revista de Filosofía 80, no. 1 (2020): 87-105. 
vivenciado el temor (phóbos) en el horizonte de la tragedia, purificación que, en definitiva, está orientada a un alivio afectivo de los espectadores.

Incluso podríamos agregar que ya en el estudio práctico de las pasiones a partir de la Retórica es posible extraer variados elementos que permitirían una cierta sanación de las pasiones incorrectamente sentidas cuando los aplicamos en nosotros mismos. El análisis de la ira, por ejemplo, viene acompañado por ciertas preguntas fundamentales: ¿por qué siento ira ahora?, ¿con respecto a qué o a quién?, ¿puedo cambiar ese sentimiento de ira que ahora me invade hacia una pasión contraria como la calma?, ¿cuál es el fundamento del desprecio que creo percibir y que me duele?, ¿aquel que creo que me despreció quiso realmente hacerlo?, ¿está mi sentimiento de ira enmarcado en algunas de las descripciones que nos brinda Aristóteles en su análisis?

Tales preguntas, que pueden ser aplicadas análogamente a las demás pasiones, recuperarían a su modo la aspiración de Gorgias, en el sentido del poder sanador de la retórica, dejando en entredicho la comparación platónica del Gorgias de la retórica con la culinaria. ${ }^{21}$ Podríamos decir a partir de Aristóteles que la retórica puede sanar, pero siempre circunscrita a ciertos límites que otorguen bienestar a la ciudad.

\section{Conclusiones}

El nivel comunitario de las pasiones, y su posible sanación en lo que podríamos denominar una polytherapeia, no en el sentido médico actual, en tanto uso del discurso persuasivo con vistas al mejoramiento de la vida en comunidad, debe ser encomendada a un arte, la téchne rhetoriké, que a efectos de estos tratamientos supone un orador con buena intención (Retórica 1355b 17-18), que sepa que no se debe hacer lo malo y conozca la preeminencia de lo justo sobre su contrario, y que, además, sea considerado como sensato, benevolente y virtuoso por el auditorio (1378a 8), y de este modo superar lo realizado por demagogos y logógrafos mal intencionados que tanto daño hacen a la vida política. Lo más relevante es que esta posibilidad de tratamiento de las pasiones por medio del lenguaje apoya sustantivamente la tesis de que las páthe consideradas en Retórica tienen un componente cognitivo de importancia, toda vez que ciertas pasiones pueden ser obedientes a la razón, de una manera semejante a como se escucha el consejo del padre o de los amigos buenos.

La retórica concebida como un arte se manifiesta como el medio lingüístico por el cual las pasiones, que tienen un carácter eminentemente individual, pueden ser transmitidas a la colectividad. En este sentido, solo el ser humano, a diferencia de los demás animales, tiene un

21 Jamie Dow argumenta en favor de esta posición intermedia que asume Aristóteles entre Gorgias y Trasímaco, por una parte, y Platón, por la otra. Passions and Persuasion in Aristotle's Rhetoric (Oxford: Oxford University Press, 2015). Propone, en definitiva, una consideración normativa de la retórica aristotélica, y así esta téchne puede contribuir a los buenos juicios en tribunales y a una adecuada deliberación en la asamblea, en atención a los tipos de cognición presentes en las pasiones (cap. 10), las que el autor explica unitariamente a partir de la dimensión intrínsecamente intencional y representacional del placer y el dolor (cap. 9). 
lenguaje que le permite no solo expresar el dolor y el placer, sino que también puede orientarlo hacia fines que no se cierran en el dolor y el placer como una afección meramente individual, y así puede ampliarse a la casa y la ciudad (Política 1253a 10-18).

Además, para Aristóteles, no solo es importante el conocimiento de las pasiones dolorosas por ellas mismas, sino que conociéndolas es como expresan todo su potencial terapéutico, al poder reconducir al auditorio hacia la pasión contraria. Así pues, a partir de lo dicho, es posible concluir que el tratamiento de las pasiones dolorosas puede conducir a su sanación mediante el uso del lenguaje persuasivo, al poder orientarlas de manera adecuada hacia su contrario.

En las difíciles condiciones que actualmente atraviesa la humanidad, producto de la pandemia a la que nos vemos enfrentados, el conocimiento y tratamiento de las pasiones dolorosas aporta una vía de resolución de dificultades urgentes que no solo afectan a los individuos, sino también a las sociedades miradas en su conjunto, sobre todo, al tener en consideración la relevancia de habérnoslas con nuestras emociones de una manera más próxima y exigente, debido al hecho de que se hace más dificultoso distanciarse de ellas o distraernos en otros quehaceres e intentar minimizarlas o ignorarlas.

\section{Bibliografía}

Aristóteles. Ética a Nicómaco. Traducido por María Araujo y Julián Marías. Madrid: Centro de Estudios Constitucionales, 1994.

Aristóteles. Acerca del alma. Traducido por Tomás Calvo Martínez. Madrid: Gredos, 1988.

Aristóteles. Ética eudemia. Traducido por Carlos Megino. Madrid: Alianza, 2002.

Aristóteles. Política. Traducido por Julián Marías y María Araujo. Madrid: Centro de Estudios Constitucionales, 1989.

Aristóteles. Retórica. Traducido por Quintín Racionero. Madrid: Gredos, 1990.

Aristóteles. Retórica. Traducido por Alberto Bernabé. Madrid: Alianza, 1998.

Aristóteles. Aristotelis Ars Rhetorica. Edición crítica de W. D. Ross. Oxford: Oxford University Press, 1986.

Aristóteles. Aristote Rhétorique. Traducido por Médéric Dufour. París: Les Belles Lettres, 1991.

Aristóteles. Poética. Traducido por Valentín García Yebra. Madrid: Gredos, 1974.

Cooper, John. "An Aristotelian Theory of the Emotions". En Essays on Aristotle's Rhetoric. Editado por Amelie Oksenberg Rorty, 238-257. Berkeley: University of California Press, 1996.

Covarrubias Correa, Andrés. “Confianza y temor en Aristóteles”. Philosophia: Revista de Filosofía 80, no. 1 (2020): 87-105. https://revistas.uncu.edu.ar/ojs3/index.php/philosophia/article/view/3642.

Dow, Jamie. Passions and Persuasion in Aristotle's Rhetoric. Oxford: Oxford University Press, 2015. https://doi. org/10.1093/acprof:oso/9780198716266.001.0001

Fortenbaugh, William. “Aristotle’s Rhetoric on Emotions”. En Articles on Aristotle: Psychology \& Aesthetics. Editado por Jonathan Barnes, Malcolm Schofield y Richard Sorabji, 133-153. Londres: Duckworth, 1979.

Fortenbaugh, William. Aristotle on Emotion: A Contribution to Philosophical Psychology, Rhetoric, Poetics, Politics, and Ethics. Londres: Duckworth, 1975.

Frede, Dorothea. "Mixed Feelings in Aristotle's Rhetoric". En Essays on Aristotle's Rhetoric. Editado por Amelie Oksenberg Rorty, 258-285. Berkeley: University of California Press, 1996.

Godoy, Óscar. La democracia en Aristóteles: Los orígenes del régimen republicano. Santiago de Chile: Universidad Católica de Chile, 2012.

Hutchinson, Douglas. "Doctrines of the Mean and the Debate Concerning Skills in Fourth-Century Medicine, Rhetoric and Ethics". Apeiron 21 (1988): 17-52. https://doi.org/10.1515/APEIRON.1988.21.2.17.

Jacob, Bernard. "What if Aristotle Took Sophists Seriously? New Readings in Aristotle's Rhetoric". Rhetoric Review 14, no. 2 (1996): 237-252. https://doi.org/10.1080/07350199609389063. 
Lausberg, Heinrich. Manual de retórica literaria: Fundamentos de una ciencia de la literatura. Vol. 1. Traducido por José Pérez Riesco. Madrid: Gredos, 1990.

López Eire, Antonio. Sobre el carácter retórico del lenguaje y de cómo los antiguos griegos lo descubrieron. México: Universidad Nacional Autónoma de México, 2005.

Meyer, Michel. The Modernity of Rhetoric. Norwell: Kluwer, 1989. https://doi.org/10.1007/978-94-009-2593-9_1.

Nussbaum, Martha. La terapia del deseo. Teoría y práctica en la ética helenística. Traducido por Miguel Candel. Barcelona: Paidós, 2003.

Penrot, Laurent. La Retórica en Grecia y Roma. México: Universidad Nacional Autónoma de México, 2013.

Pujante, David. Manual de retórica. Traducido por Karina Castañeda y Oswaldo Hernández. Madrid: Castaglia, 2003.

Price, Robert. "On the Place of Validity". Philosophy and Rhethoric, 25 (1992): 341-350. https://doi.org/10.1086/ psaprocbienmeetp.1992.2.192848.

Schütrumpf, Eckart. "Non-Logical Means of Persuasion in Aristotle's Rhetoric and Cicero's De oratore". En Peripatetic Rhetoric After Aristotle. Editado por William Fortenbaugh y David Mirhady, 95-110. New Brunswick: Transaction Publishers, 1994.

Sellés-Dauder, Juan Fernando. Los filósofos y los sentimientos. Pamplona: Universidad de Navarra, 2010.

Trueba Atienza, Carmen. "La teoría aristotélica de las emociones". Signos Filosóficos 11, no. 22 (2009): 147-170.

Vigo, Alejandro. Aristóteles: Una Introducción. Santiago de Chile: Instituto de Estudios de la Sociedad, 2006.

Yack, Bernard. "Rhetoric and Public Reasoning: An Aristotelian Understanding of Political Deliberation". Political Theory 34, no. 4 (2006): 417-438. https://doi.org/10.1177/0090591706288232. 